\title{
Exploration of minima on the $\mathrm{C}_{7} \mathrm{H}_{7}^{+}$surface: Structural, stability- and charge-related considerations
}

\author{
KIEW S KHARNAIOR and R H DUNCAN LYNGDOH* \\ Department of Chemistry, North-Eastern Hill University, Shillong 793 022, India \\ e-mail: rhdl@nehu.ac.in
}

MS received 25 September 2013; revised 5 March 2014; accepted 13 March 2014

\begin{abstract}
Four ab initio quantum chemical approaches were used to study the relative stability, structure and charge distribution of 33 putative $\mathrm{C}_{7} \mathrm{H}_{7}^{+}$isomeric structures. All of them proved to be true minima on the $\mathrm{C}_{7} \mathrm{H}_{7}^{+}$ potential energy surface. Stability orders for all 33 isomers as derived from the four computational strategies used here showed a fair degree of correlation with one another, especially between the density functional theory (DFT) and MP2 data sets. These computational results reproduced the stability order tropyl $>$ benzyl $>$ mtolyl $>$ o-tolyl $>$ p-tolyl derived from previous results of high-level theory and experiment. Structural features such as aromaticity, cyclic or acyclic structure, allylic and other conjugation effects, carbon atom hybridization state and small ring strain were invoked as factors which augment or diminish cation stability. The NICS index for aromaticity could distinguish well between aromatic, non-aromatic and anti-aromatic ring moieties in the cations. Application of these factors proved to be quite consistent in rationalizing in a broad manner the calculated stability orders for the entire set. Joint consideration of the optimized geometry and charge distribution led to the choice of a single canonical form or hybrid best representing each $\mathrm{C}_{7} \mathrm{H}_{7}^{+}$isomer.
\end{abstract}

Keywords. $\quad \mathrm{C}_{7} \mathrm{H}_{7}^{+}$isomers; cation stability; cation geometry; charge distribution; NICS; hybridization state; Hartree-Fock; B3LYP; MP2.

\section{Introduction}

Carbocations of the formula $\mathrm{C}_{n} \mathrm{H}_{n}^{+}$are interesting due to the unique stoichiometry. Isomers and rearrangement reactions for numerous families of such systems with $n=3,4,5,6$ and 7 have been recently studied using $a b$ initio and density functional theory (DFT) methods. ${ }^{1,2}$ The $\mathrm{C}_{7} \mathrm{H}_{7}^{+}$cation system has received much experimental and theoretical attention. Many $\mathrm{C}_{7} \mathrm{H}_{7}^{+}$isomers have been generated, detected and studied by mass spectrometry. ${ }^{3}$ This study seeks to isolate numerous minima on the $\mathrm{C}_{7} \mathrm{H}_{7}^{+}$energy surface in order to gauge the effect of certain structural features upon the calculated stability of various isomers. This study goes on to use the calculated geometries and charge distribution to propose the valence bond form best representative of each species.

\subsection{Generation of $\mathrm{C}_{7} \mathrm{H}_{7}^{+}$carbocations}

$\mathrm{C}_{7} \mathrm{H}_{7}^{+}$species may be formed from neutral $\mathrm{C}_{7} \mathrm{H}_{7} \mathrm{X}$ species (where $\mathrm{X}=\mathrm{H}$, halide or other leaving group)

\footnotetext{
*For correspondence
}

by loss of a hydride or leaving group. Such reactions in superacid medium could in principle lead to generation of $\mathrm{C}_{7} \mathrm{H}_{7}^{+}$cations. Mass spectrometry conditions can cause various precursors to ionize and yield $\mathrm{C}_{7} \mathrm{H}_{7}^{+}$species by loss of hydrogen atoms, $\mathrm{CH}_{3}, \mathrm{NO}_{2}$, $\mathrm{C}_{2} \mathrm{H}_{2}, \mathrm{C}_{2} \mathrm{H}_{4}$ etc. The $\mathrm{C}_{7} \mathrm{H}_{7}^{+}$species may isomerize and fragment further. Hydrocarbon precursors include toluene, ${ }^{4-9}$ ethylbenzene, ${ }^{4,10-12}$ propylbenzene, ${ }^{13} n$ butylbenzene ${ }^{14}$ and $o$-xylene. ${ }^{10} \mathrm{C}_{7} \mathrm{H}_{7}^{+}$species known to be thus generated include the benzyl, tropyl, 3 tolyl and norbornadienyl cations. ${ }^{4,6-8,10,11,15}$ Halotoluenes also undergo similar reactions. ${ }^{15,16}$ Benzyl, m-tolyl and ptolyl cations were produced from ionized benzyl bromide and $m$ - and $p$-nitrotoluene. ${ }^{15}$ Benzyl and tropyl cations predominate in another such product mixture. ${ }^{4}$ Interconversion between isomers, notably, between benzyl and tropyl, ${ }^{5-7,9,12}$ has also been studied.

Unimolecular decomposition of larger species under conditions of mass spectrometry can generate $\mathrm{C}_{7} \mathrm{H}_{7}^{+}$ species. Decomposition of excited $\mathrm{C}_{8} \mathrm{H}_{10}^{+}$isomers (ethylbenzene, methylcycloheptatriene, $o_{-}^{-}, p$ - and $m$ xylene ions) yields $\mathrm{C}_{7} \mathrm{H}_{7}^{+}$ions as a major fragment including tropyl and benzyl cations. ${ }^{17}$ Near the reaction threshold, both benzyl and tropyl cations are produced, but only the benzyl ion is observed at higher internal energies. Alkylbenzene ion decomposition yields 
increasing benzyl ion production with increase in size of the alkyl substituent. ${ }^{11,13,14}$

\subsection{Relative stability of $\mathrm{C}_{7} \mathrm{H}_{7}^{+}$isomers}

Experimental efforts to estimate heats of formation for $\mathrm{C}_{7} \mathrm{H}_{7}^{+}$cations often use the benzyl cation as a starting point, and various values have been assigned to its heat of formation, where the value of $919 \pm 5 \mathrm{~kJ} \mathrm{~mol}^{-1}$ is well-accepted. ${ }^{4}$ Heat of formation of the tropyl cation is difficult to determine due to side reactions apart from unimolecular dissociations yielding the tropyl ion, and the various experimental results do not coincide. ${ }^{7,17,18}$ Table 1 gathers data (heats of formation and energies relative to tropyl ion) from various experimental and computational sources for the five best-known isomers - the tropyl, benzyl, o-tolyl, m-tolyl and p-tolyl cations.

MINDO/3 studies ${ }^{19,20}$ gave the stability order of tropyl $>$ benzyl $>o$-tolyl $>m$-tolyl $>p$-tolyl. The MINDO/3 tropyl-benzyl energy difference $(24.8 \mathrm{kcal}$ $\mathrm{mol}^{-1}$ ) is larger than other more accurate estimates, such as the G2(MP2) value of $6.9 \mathrm{kcal} \mathrm{mol}^{-1} .^{21,22} \mathrm{MP} 4$ values of relative energies for these five isomers ${ }^{23}$ led to the same stability order as above, though MP4based heats of formation (table 1) differ markedly from MINDO/3 values. The CCSD(T) level of theory ${ }^{24}$ gave the same stability order, where computed energy differences between isomers (table 1) approach MP4 values. One of the experimentally obtained stability orders ${ }^{25}$ was similar to the theoretically derived one, except for the ranks of the $m$-tolyl and $p$-tolyl cations.

\subsection{Scope of this study}

The $\mathrm{C}_{7} \mathrm{H}_{7}^{+}$potential energy surface is explored here by proposing 33 isomeric structures which hold promise of being true minima-the largest collection of carbocation isomers ever studied together so far. The appreciable number of carbon atoms present (seven) allows for a large number of isomers to arise from the $\mathrm{C}_{7} \mathrm{H}_{7}^{+}$ stoichiometry, which can incorporate a wide range of different structural features. The 33 isomers selected here do not presume to be an exhaustive list. These include the few more stable structures already studied experimentally and computationally. Most of the other structures proposed here have never been studied yet. Many of these hypothetical structures are expected to be of very high energy and inaccessible to experimental detection or characterization by current methods, although all are predicted to be true minima. Computational study is therefore needed to predict their molecular structure, stability and charge distribution, with the hope that such predictions may be borne out by experiment some day (to some extent at least).

A variety of pertinent structural features (stabilizing or destabilizing) will be invoked to help rationalize calculated stability orders at least qualitatively in a consistent manner. Calculations of equilibrium geometry and charge distribution can also assist in assignment of the most suitable valence bond structure (whether single canonical form or hybrid) for each species, something which qualitative and general concepts alone cannot be relied upon to accomplish.

Figures 1 and 2 portray valence bond structures of the $33 \mathrm{C}_{7} \mathrm{H}_{7}^{+}$isomers expected to yield true minima. The numbering from $\mathbf{1}$ to $\mathbf{3 3}$ follows the stability order obtained here by calculation at the MP2/cc-pVDZ level. The canonical form/hybrid shown for each isomer is the one proposed here as the most suitable by joint consideration of both optimized geometry and charge distribution.

Table 1. Heat of formation $\Delta H_{\mathrm{f}}^{o}$ (in brackets) and relative energies $\Delta E_{\mathrm{r}}$ of the tropyl, benzyl, and the three tolyl cation isomers (in kcal mol${ }^{-1}$ ).

\begin{tabular}{|c|c|c|c|c|c|c|c|c|c|}
\hline \multirow[b]{2}{*}{ Cation } & \multicolumn{6}{|c|}{ Theory } & \multicolumn{2}{|c|}{ Experiment } & \multirow{2}{*}{$\begin{array}{l}\text { This work } \\
\Delta \mathrm{E}_{r}(\mathrm{MP} 2)\end{array}$} \\
\hline & $\mathrm{E}_{t}$ & $\Delta \mathrm{E}_{\mathrm{r}}$ & $\mathrm{E}_{t}$ & $\Delta \mathrm{E}_{\mathrm{r}}$ & $\mathrm{E}_{t}$ & $\Delta \mathrm{E}_{\mathrm{r}}$ & $\mathrm{E}_{t}$ & $\Delta \mathrm{E}_{\mathrm{r}}$ & \\
\hline Tropyl & $(195.6)^{\mathrm{a}}$ & 0 & $(214.1)^{b}$ & 0 & $(212.7)^{\mathrm{c}}$ & 0 & $(212.2)^{\mathrm{d}}$ & 0 & 0 \\
\hline Benzyl & $(220.4)^{\mathrm{a}}$ & 24.8 & $(219.6)^{b}$ & 5.5 & $(219.6)^{c}$ & 6.9 & $(219.9)^{d}$ & 7.7 & 10.6 \\
\hline O-tolyl & $(231.8)^{\mathrm{a}}$ & 36.2 & $(260.3)^{b}$ & 46.2 & $(261.7)^{\mathrm{c}}$ & 49.0 & $(258.1)^{\mathrm{e}}$ & 49.9 & 51.3 \\
\hline M-tolyl & $(236.1)^{\mathrm{a}}$ & 40.5 & $(261.2)^{b}$ & 47.1 & $(263.1)^{c}$ & 50.4 & $(260.8)^{\mathrm{e}}$ & 52.6 & 52.7 \\
\hline P-tolyl & $(236.6)^{\mathrm{a}}$ & 41.0 & $(263.1)^{b}$ & 49.0 & $(265.3)^{c}$ & 52.6 & $(258.8)^{\mathrm{e}}$ & 50.6 & 54.9 \\
\hline
\end{tabular}

\footnotetext{
${ }^{\mathrm{a}}$ Reference ${ }^{20}$

${ }^{\mathrm{b}}$ Reference ${ }^{23}$

${ }^{c}$ Reference ${ }^{24}$

${ }^{\mathrm{d}}$ Reference ${ }^{18}$

${ }^{\text {e }}$ Reference ${ }^{25}$
} 


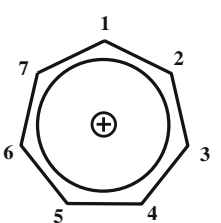

tropyl<smiles>C=C1C=C[C+]([N+]=O)C=C1</smiles>

2

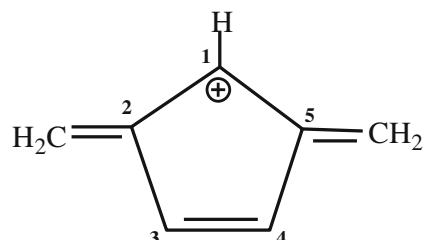

2,5-dimethylenylcyclopentenyl

3

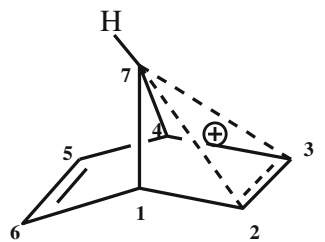

7-norborna-1,4-dienyl

4

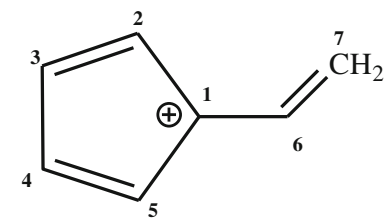

1-vinylcyclopentadienyl

5

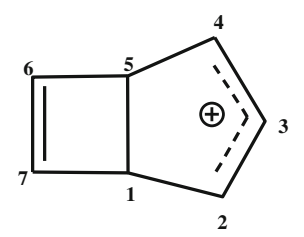

bicyclo[3.2.0]heptadienyl

6<smiles>Cc1ccc([O-])cc1</smiles>

7<smiles>Cc1ccc([O+])cc1</smiles>

8

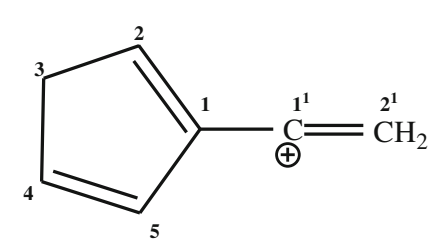

$1^{1}$ vinyliumcyclopenta-1,4-diene

9<smiles>C=CC1=C(C=C)[CH]1</smiles>

2,3-divinylcyclopropenyl

12

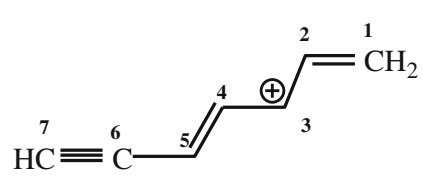

hepta-1,4,-diene-6-ynyl

15<smiles>Cc1ccc(O)cc1</smiles>

10

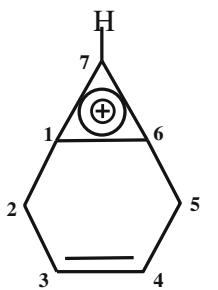

bicyclo[4.1.0]heptadienyl

13

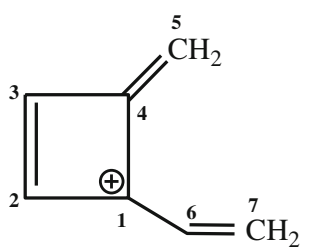

4-methylene-1-vinylcyclobutenyl

16

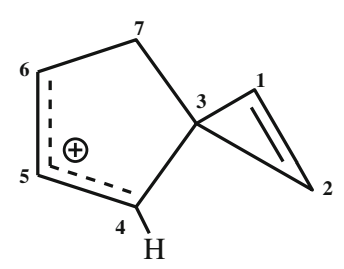

spiro[2.4]hept-1,6-dienyl

14

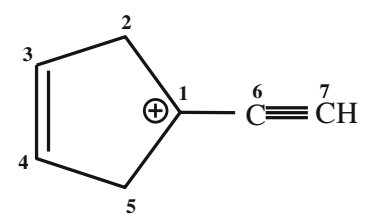

1-ethynylcyclopent-3-enyl 17

Figure 1. VB structures of $\mathrm{C}_{7} \mathrm{H}_{7}^{+}$isomers $\mathbf{1}$ to 17. 


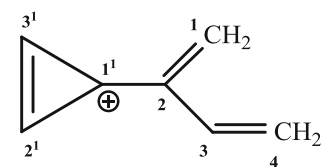

$1^{1}$ (but-1,3-dienyl)cyclopropenyl 18

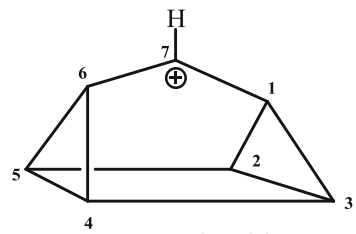

tetracyclo[3.2.0.0 $\left.0^{2,7} \cdot 0^{4,6}\right]$ heptyl

21<smiles>C#CC#CC(C)C</smiles>
24<smiles>C=CC=CC=C</smiles>

1,2,4,6-heptatetraenyl

19

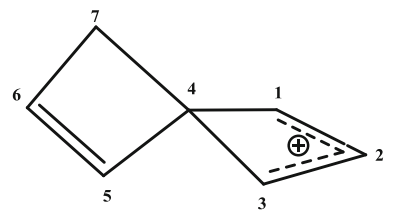

spiro[3.3]heptadienyl

22

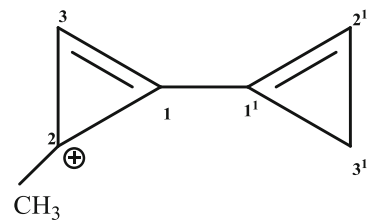

cycloprop-1 ${ }^{1}$-enyl-2-methylcyclopropenyl

25

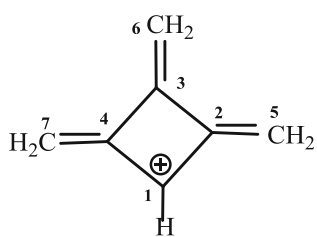

trimethylenylcyclobutyl 20

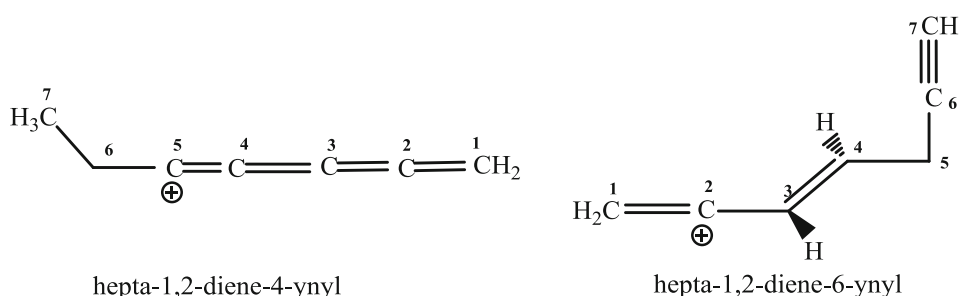

27

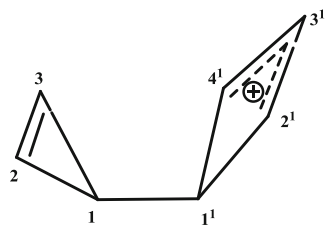

$1,1^{1}$-cyclopropenylcyclobutenyl 30

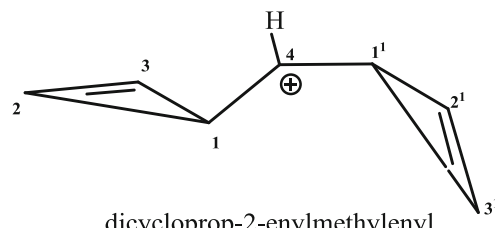

dicycloprop-2-enylmethylenyl

31

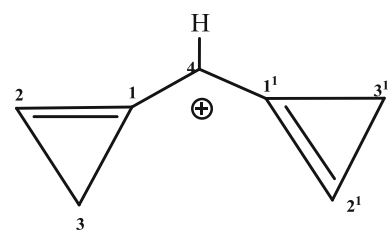

dicycloprop-1-enylmethylenyl

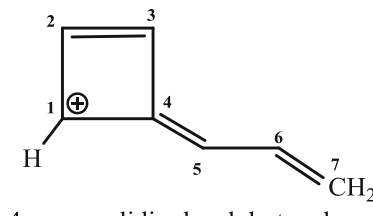

4-propenylidinylcyclobutenyl

23

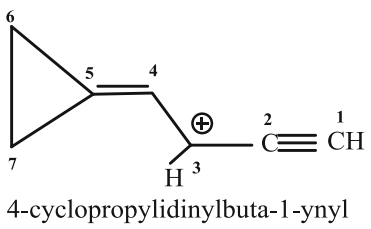

26

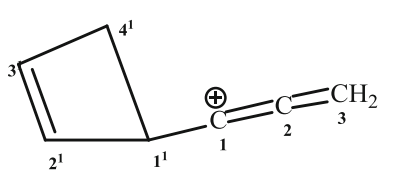

1-(cyclobut-2 ${ }^{1}$-enyl)propa-1,2-dienyl 29

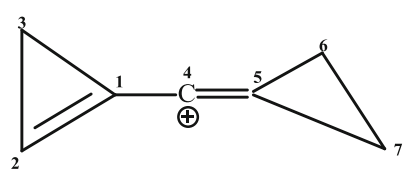

cyclopropenylcyclopropanylidinylmethylenyl 32

Figure 2. VB structures of $\mathrm{C}_{7} \mathrm{H}_{7}^{+}$isomers $\mathbf{1 8}$ to 33 . 


\section{Approach and Computational Details}

The approach and aims of this study may be summarized as follows:

1. Relative stability of the 33 isomers is estimated using four $a b$ initio strategies, and the four stability orders compared to see if the methods coincide in their predictions.

2. Effects of pertinent structural features (see 2.1) upon stability of the isomers are gauged qualitatively to see if such criteria can be consistently applied to help explain the stability trends for the entire set of 33 isomeric minima.

3. Optimized geometry is considered along with charge distribution for each cation to propose the resonance hybrid or canonical form best representative of the system. It must be noted that such suitable structures cannot be assigned a priori simply from general considerations alone, but require input from actual calculations to arrive at more reasonable and reliable assignments.

4. Aromaticity of a cyclic moiety within a $\mathrm{C}_{7} \mathrm{H}_{7}^{+}$ isomer is quantified by employing the nucleusindependent chemical shift (NICS) ${ }^{26,27}$ index (the negative of the isotropic magnetic shielding at a particular central point within a ring moiety).

5. The natural hybrid orbital (NHO) approach ${ }^{28,29}$ gives clues to the hybridization state of a given carbon atom with regard to bonding with a neighbouring carbon atom. Hybridization state is expressed as the number of $2 p$-orbitals mixed with a single $2 s$ orbital in the given carbon atom. This number (1, 2 and 3 for $s p, s p^{2}$ and $s p^{3}$ hybrids, respectively) may be fractional, and the $s: p$ ratio is written as $s^{\wedge} N p$ (where $N p$ is the number of $2 p$-orbitals mixing with the $2 s$ orbital). Each carbon atom may have two or three $s: p$ ratio values, depending on the atom(s) which it is bonded to.

Structures of all 33 isomers were optimized at the HF/6-31G(d) level, at the B3LYP theory DFT level ${ }^{30-32}$ using the 6-31G(d) and 6-31G(d,p) basis sets, and at the MP2/cc-pVDZ level, all using the Gaussian 2003 program suite. ${ }^{33}$ All 33 structures were confirmed as true minima on the $\mathrm{C}_{7} \mathrm{H}_{7}^{+}$energy surface by vibrational analyses which furnished the zero point energy (ZPE) corrections. Scaling factors used here ${ }^{34}$ were 0.9135 for the HF/6-31G(d) set, 0.9806 for the B3LYP/6-31G(d) set, 0.9613 for the B3LYP/6-31G(d,p) set and 0.9790 for the MP2/cc-pVDZ set.

ZPE-corrected relative energies $\Delta E_{\mathrm{r}}$ of each isomer at $0^{\circ} \mathrm{K}$ were calculated with respect to the most stable tropylium cation 1. ZPE-corrected total free energies provided ZPE-corrected relative free energies $\Delta G_{\mathrm{r}}$ for each isomer relative to $\mathbf{1}$. Geometry features of the optimized structures invoked here include bond lengths, bond angles and dihedral angles. Natural population analysis ${ }^{35}$ or NPA was used to derive point atomic charges on the atoms of each species on the basis of the MP2/cc-pVDZ strategy.

The B3LYP/cc-pVDZ strategy yielded optimized structures for all the 33 isomers, for which the NICS index was computed at the centroid of each ring moiety (called NICS $(0)$ ) and also at a point $1.0 \AA$ above the centroid (called NICS(1), and used to arrive at a better estimate of only the pi electron contributions to aromaticity).

\subsection{Structural features associated with stability}

Carbocation stability is chiefly related to delocalization of positive charge, but may also be related to neutral moieties present. Aromatic delocalization of positive charge is seen in the tropyl cation $\mathbf{1}$ and in isomers possessing a cyclopropenyl cation moiety. Allylic resonance involving the $-\mathrm{CH}=\mathrm{CH}-\mathrm{CH}^{+}-$moiety stabilizes the ion through delocalization of positive charge. This may also happen via acyclic conjugation of a multipi electron system with a positively charged centre, as when a 1,3-butadiene chain conjugates to a positively charged carbon. Benzylic resonance is more effective than allylic resonance. Species with two or more equivalent resonance structures are further stabilized as a result. Pi electron delocalization is favoured by planarity which allows maximal overlap between adjacent $2 p z$ atomic orbital lobes. Hybridization state of a positively charged carbon deserves mention, where an $s p^{2}$ carbon has greater capacity to host positive charge than an $s p$ carbon. Non-classical resonance is also stabilizing, when a sigma bond and a pi bond interconvert, both linked to a carbon positive charge. Delocalization of positive charge is destabilizing in an anti-aromatic moiety such as the cyclopentadienyl cation.

Neutral moieties may also stabilize or destabilize a cation. Neutral conjugated pi bond systems are a stabilizing feature. Strained neutral cycloalkane moieties are destabilizing, where the cyclopropyl and cyclobutyl groups are noteworthy. Strain effects are enhanced by a double bond in small carbocycles such as the cyclopropenyl and cyclobutenyl rings.

It is not immediately possible to quantify all these individual structural effects and put them together to arrive at the quantitative stability orderings obtained here by quantum theory. This would require estimation of the energy component for each separate effect 
and also further require knowledge of the weight for each separate effect when all are considered together. It is deemed sufficient here to attempt quantification of aromaticity by the NICS index, which itself has drawn criticism for yielding poor quantitative correlation with other measures of aromaticity such as aromatic stabilization energy and the harmonic oscillator (or HOMA) index for aromaticity. It will be seen, however, that the NICS index does serve well here to screen between aromatic, non-aromatic and anti-aromatic ring moieties present in the $\mathrm{C}_{7} \mathrm{H}_{7}^{+}$isomers.

\section{Results and Discussion}

The 33 isomers are numbered as per the stability order obtained by the MP2/cc-pDVZ method. Figures S1 to $\mathrm{S} 3$ give Gauss View representations of the MP2/ccpVDZ optimized structures for these 33 carbocation isomers. The file SuppInfoGeom (supplementary information) stores the $\mathrm{X}, \mathrm{Y}$ and $\mathrm{Z}$ Cartesian coordinates of the optimized geometries of all 33 isomers as obtained by all the four methods used for calculation here. Tables S1 to S4 list the total energies $E_{t}$, ZPE corrections $E_{Z P E}$, corrected total energies $E_{t}(\mathrm{cr})$, total free energies $G_{t}$ and ZPE-corrected total free energies $G_{t}(\mathrm{cr})$ for all 33 cations as obtained by the four calculation strategies. Tables S5 to S9 give the results of NHO analysis for the carbon atoms present, listing the relevant ring moiety, the carbon atom of interest, the various bond orbitals, the percentages of $2 s$ and $2 p$ character, the $s: p$ ratio (written as $s^{\wedge} N p$ ), and the atomic charge $Q_{c}$ on the carbon atom of interest.

\subsection{Relative stability of $\mathrm{C}_{7} \mathrm{H}_{7}^{+}$isomers}

Tables 2 and 3 present, respectively, values of the relative energies $\Delta E_{r}$ and of the relative free energies $\Delta G_{r}$ (both ZPE-corrected) for the 33 cations, calculated at the HF/6-31G(d), B3LYP/6-31G(d), B3LYP/6$31 \mathrm{G}(\mathrm{d}, \mathrm{p})$ and MP2/cc-pVDZ levels, all taken relative to the most stable tropylium cation $\mathbf{1}$. For each case, the relative energy $\Delta E_{r}$ is derived from the ZPEcorrected total electronic energy $E_{t}$ (corr), and the relative free energy $\Delta G_{r}$ derived from the ZPE-corrected total free energy $G_{t}$ (corr). Values of $\Delta E_{r}$ range up to $123.29,114.13,113.94$ and $122.70 \mathrm{kcal} / \mathrm{mol}$ at the HF/6-31G(d), B3LYP/6-31G(d), B3LYP/6-31G(d,p) and MP2/cc-pVDZ levels of theory, respectively. It is clear that the high energy spectrum for minima on the $\mathrm{C}_{7} \mathrm{H}_{7}^{+}$surface includes species which, though true minima, are predicted to be so unstable as to escape detection by known experimental methods.

B3LYP/6-31G(d) and B3LYP/6-31G(d,p) values of $\Delta E_{r}$ are very similar (figure $\mathrm{S} 4$ ), so this DFT method is rather insensitive to change of basis set from 6-31G(d) to 6-31G(d,p). The HF/6$31 G(d)$ and MP2/cc-pVDZ methods present differences in stability order. The plot of HF/6-31G(d) values of $\Delta E_{r}$ against the MP2/cc-pVDZ values (figure S5) shows some spread (correlation coefficient $=0.976$ ). The plot of MP2/cc-pVDZ values of $\Delta E_{r}$ versus the B3LYP/6-31G(d,p) values gives a correlation coefficient of 0.979 (figure S6). Replacing the $\Delta E_{r}$ values by the corresponding free energy terms $\Delta G_{r}$ does not affect the trends displayed. Figure S7 shows the MP2/cc-pVDZ values of $\Delta G_{r}$ values correlate well with the corresponding $\Delta E_{r}$ values (correlation coefficient $=0.998$ ).

Previous results ${ }^{18,20,23-25}$ given in table 1 largely correlate with the stability orders obtained computationally here. Consensus in stability order from the limited experimental and computational results available so far emerges as tropyl $>$ benzyl $>o$-tolyl $>m$-tolyl $>p$ tolyl, which order is borne out here by all four calculation strategies. This limited data set is now extended to include the 28 other hitherto unstudied $\mathrm{C}_{7} \mathrm{H}_{7}^{+}$isomers into one single comprehensive investigation.

Aromaticity is a major stabilizing factor for cyclic cations $1,2,7,8,10,12$ and 13 , all ranking high in the stability order. This applies chiefly to the tropyl cation 1, and also to cations 12 and 13 containing an aromatic cyclopropenyl ion moiety. These cations exhibit aromatic delocalization of positive charge, and the strain-free tropyl ion benefits more than the strained cations 12 and 13. Presence even of a neutral benzene ring is stabilizing, as in cation $\mathbf{2}$ (disregarding conjugation with the methylene positive charge), and also in the tolyl ions 7, 8 and $\mathbf{1 0}$ (all retaining a formal aromatic sextet despite deformation of the benzene ring). Unstrained non-aromatic five- and six-membered ring moieties having delocalized positive charge and pi bonds stabilize cations $\mathbf{3 , 5}, \mathbf{6}$ and $\mathbf{9}$.

Allylic resonance involving the delocalized charged moiety $-\mathrm{CH}=\mathrm{CH}-\mathrm{CH}^{+}-$stabilizes cations $3, \mathbf{5}, \mathbf{6}, \mathbf{1 2}$, 16, 18, 20 and 23. Here, cations 16, 18, 20 and 23 are less stable due to small ring strain. Often, the allyl moiety is itself conjugated to a pi system, so the net delocalization may be termed as multiple pi bond resonance.

Non-classical ions involve sigma-pi overlap with inter-conversion between pi and sigma bonds, while sigma-sigma overlap causes conversion of a sigma bond to another sigma bond. These effects are all 
Table 2. ZPE corrected relative energies $\Delta E_{r}$ of the 33 isomers of the $\mathrm{C}_{7} \mathrm{H}_{7}^{+}$system as calculated by the HF/6-31G(d), B3LYP/6-31G(d), B3LYP/6$31 \mathrm{G}(\mathrm{d}, \mathrm{p})$ and MP2/cc-pVDZ levels of theory (in $\mathrm{kcal} \mathrm{mol}^{-1}$ ).

\begin{tabular}{lcccc}
\hline Isomers & HF/6-31G* & B3LYP/6-31G* & B3LYP/6-31G** & MP2/cc-pVDZ \\
\hline $\mathbf{1}$ & 0 & 0 & 0 & 0 \\
$\mathbf{2}$ & 5.70 & 9.08 & 9.06 & 10.65 \\
$\mathbf{3}$ & 33.84 & 36.24 & 36.15 & 38.30 \\
$\mathbf{4}$ & 47.65 & 52.09 & 51.85 & 39.12 \\
$\mathbf{5}$ & 41.14 & 46.18 & 45.98 & 49.13 \\
$\mathbf{6}$ & 50.14 & 52.84 & 52.58 & 50.34 \\
$\mathbf{7}$ & 53.96 & 50.47 & 50.35 & 51.30 \\
$\mathbf{8}$ & 56.36 & 52.08 & 51.90 & 52.67 \\
$\mathbf{9}$ & 49.82 & 49.62 & 49.20 & 54.41 \\
$\mathbf{1 0}$ & 57.82 & 54.21 & 54.05 & 54.92 \\
$\mathbf{1 1}$ & 67.69 & 64.58 & 64.47 & 56.60 \\
$\mathbf{1 2}$ & 42.71 & 52.38 & 52.19 & 57.22 \\
$\mathbf{1 3}$ & 48.44 & 58.13 & 58.03 & 57.74 \\
$\mathbf{1 4}$ & 60.06 & 60.48 & 60.03 & 59.71 \\
$\mathbf{1 5}$ & 59.16 & 59.27 & 59.06 & 65.61 \\
$\mathbf{1 6}$ & 57.59 & 61.05 & 60.86 & 65.64 \\
$\mathbf{1 7}$ & 62.62 & 64.31 & 63.87 & 66.66 \\
$\mathbf{1 8}$ & 56.47 & 66.87 & 66.49 & 68.81 \\
$\mathbf{1 9}$ & 62.98 & 58.68 & 58.64 & 72.01 \\
$\mathbf{2 0}$ & 68.11 & 66.95 & 66.85 & 73.74 \\
$\mathbf{2 1}$ & 83.36 & 84.22 & 83.90 & 75.98 \\
$\mathbf{2 2}$ & 80.33 & 85.12 & 84.84 & 80.66 \\
$\mathbf{2 3}$ & 71.81 & 75.28 & 75.00 & 81.88 \\
$\mathbf{2 4}$ & 80.00 & 75.14 & 75.17 & 82.19 \\
$\mathbf{2 5}$ & 80.38 & 84.95 & 84.84 & 88.95 \\
$\mathbf{2 6}$ & 83.26 & 82.83 & 82.59 & 89.07 \\
$\mathbf{2 7}$ & 88.79 & 80.74 & 80.95 & 93.25 \\
$\mathbf{2 8}$ & 84.01 & 88.25 & 88.01 & 97.39 \\
$\mathbf{2 9}$ & 96.56 & 92.38 & 92.35 & 104.31 \\
$\mathbf{3 0}$ & 105.16 & 109.59 & 109.07 & 113.90 \\
$\mathbf{3 1}$ & 116.53 & 114.12 & 113.47 & 114.03 \\
$\mathbf{3 2}$ & 115.12 & 107.25 & 105.92 & \\
$\mathbf{3 3}$ & 123.29 & 114.13 & 113.94 & \\
\hline & & & & \\
\hline
\end{tabular}

stabilizing. In the norbornadienyl cation $4,^{37-41}$ the $\mathrm{C}=\mathrm{C}$ double bond on one side is delocalized by pisigma overlap with the $\mathrm{C} 7$ carbocation centre with resultant stabilization for 4 . In cation 11, the long C3-C4 sigma bond may imply non-classical resonance of this bond with the $\mathrm{C} 7$ carbocation centre.

Small ring strain destabilizes isomers having neutral cyclopropane, cyclopropene and cyclobutene rings, with the latter two unsaturated rings more strained than the former. The two cyclopropane rings in cation $\mathbf{2 1}$ constitute its chief destabilizing feature. Cyclopropene rings of cations $14,25,30,31,32$ and 33 exert a strong destabilizing effect most apparent in the high instability of isomers $\mathbf{3 0}$ to $\mathbf{3 3}$. Cyclobutene rings, though less destabilizing than cyclopropene rings, serve to destabilize cations 6, 22 and 29. Four-membered rings with positive charge destabilize cations 16, 20, 23 and 30.
Many isomers have acyclic moieties with positive charge located on an $s p$ carbon in at least one important resonance form. An $s p$ hybrid carbon has difficulty accommodating positive charge (though not negative charge - cf. the acetylide anion) compared to an $s p^{2}$ carbon. Large positive charge on an $s p$ hybrid carbon is thus a destabilizing feature. Isomers with linear moieties that contain a positively charged $s p$ carbon include cations 15, 17, 19, 24, 26, 27, 28, 29 and 32, most occurring on the less stable side.

\subsection{Various other aspects}

Joint consideration of geometry and charge distribution leads to proposal of appropriate valence bond structures for all 33 isomers, each expressed as a 
Table 3. ZPE corrected relative free energies $\Delta G_{r}$ of the 33 isomers of the $\mathrm{C}_{7} \mathrm{H}_{7}^{+}$system as calculated by the HF/6-31G(d), B3LYP/6-31G(d), B3LYP/6$31 \mathrm{G}(\mathrm{d}, \mathrm{p})$ and MP2/cc-pVDZ levels of theory (in kcal $\mathrm{mol}^{-1}$ ).

\begin{tabular}{lcccc}
\hline Isomers & HF/6-31G* & B3LYP/6-31G* & B3LYP/6-31G** & MP2/cc-pVDZ \\
\hline $\mathbf{1}$ & 0 & 0 & 0 & 0 \\
$\mathbf{2}$ & 4.59 & 7.83 & 7.86 & 9.24 \\
$\mathbf{3}$ & 31.05 & 33.23 & 33.19 & 35.11 \\
$\mathbf{4}$ & 47.80 & 51.60 & 51.41 & 38.51 \\
$\mathbf{5}$ & 37.85 & 42.39 & 42.25 & 45.25 \\
$\mathbf{6}$ & 48.68 & 50.48 & 50.27 & 47.82 \\
$\mathbf{7}$ & 49.24 & 45.51 & 45.42 & 45.91 \\
$\mathbf{8}$ & 51.19 & 46.55 & 46.25 & 47.80 \\
$\mathbf{9}$ & 45.27 & 44.58 & 44.15 & 49.00 \\
$\mathbf{1 0}$ & 52.55 & 48.70 & 48.54 & 49.06 \\
$\mathbf{1 1}$ & 66.59 & 62.99 & 62.91 & 54.97 \\
$\mathbf{1 2}$ & 37.60 & 47.16 & 47.01 & 51.80 \\
$\mathbf{1 3}$ & 46.44 & 55.45 & 55.32 & 54.91 \\
$\mathbf{1 4}$ & 56.46 & 56.28 & 55.88 & 55.17 \\
$\mathbf{1 5}$ & 53.56 & 53.84 & 53.33 & 59.51 \\
$\mathbf{1 6}$ & 52.89 & 56.04 & 55.87 & 61.10 \\
$\mathbf{1 7}$ & 57.83 & 58.82 & 58.38 & 60.65 \\
$\mathbf{1 8}$ & 50.97 & 61.05 & 60.74 & 62.87 \\
$\mathbf{1 9}$ & 56.74 & 52.53 & 52.50 & 65.64 \\
$\mathbf{2 0}$ & 63.51 & 62.03 & 61.97 & 68.27 \\
$\mathbf{2 1}$ & 81.83 & 81.99 & 81.75 & 73.12 \\
$\mathbf{2 2}$ & 77.53 & 81.63 & 81.41 & 77.09 \\
$\mathbf{2 3}$ & 66.67 & 70.19 & 69.99 & 75.69 \\
$\mathbf{2 4}$ & 71.84 & 67.07 & 67.17 & 73.68 \\
$\mathbf{2 5}$ & 73.58 & 77.60 & 77.45 & 81.56 \\
$\mathbf{2 6}$ & 77.23 & 76.29 & 76.07 & 82.30 \\
$\mathbf{2 7}$ & 80.37 & 72.60 & 72.82 & 84.59 \\
$\mathbf{2 8}$ & 75.98 & 80.51 & 80.25 & 85.09 \\
$\mathbf{2 9}$ & 90.71 & 86.45 & 86.42 & 91.25 \\
$\mathbf{3 0}$ & 100.50 & 104.06 & 103.61 & 98.60 \\
$\mathbf{3 1}$ & 109.58 & 106.55 & 105.99 & 105.96 \\
$\mathbf{3 2}$ & 108.42 & 100.91 & 98.78 & 106.90 \\
$\mathbf{3 3}$ & 116.81 & 106.78 & 106.62 & 115.09 \\
\hline & & & &
\end{tabular}

resonance hybrid or as the most important canonical form. Figures 3 to 5 give values of select bond lengths, bond angles and dihedral angles obtained from MP2/cc-pVDZ optimized geometries. Such data using the B3LYP/6-31G $(\mathrm{d}, \mathrm{p})$ method is given in figures $\mathrm{S} 8$ to S10. Charge distributions are described as NPA point atomic charges based on the MP2/cc-pVDZ strategy, as depicted in figures $\mathrm{S} 11$ to $\mathrm{S} 13$ for the 33 structures. The discussion is conducted vis-à-vis the NICS data listed in table 4, which gives the ring moiety present along with values for the $\operatorname{NICS}(0)$ and NICS(1) indices (calculated using the B3LYP/cc-pVDZ methodology).

For the most stable $D_{7 h}$ tropyl cation $\mathbf{1}$, all four strategies yield $\mathrm{C}-\mathrm{C}$ bond lengths and $\mathrm{C}-\mathrm{H}$ bond lengths which show complete delocalization of pi bonds and positive charge. These geometries compare well with results of DZP CCSD $(\mathrm{T}),{ }^{23} \mathrm{~B} 3 \mathrm{LYP} / 6-31 \mathrm{G}(\mathrm{d}, \mathrm{p})^{36}$ and
MINDO $/ 3^{19}$ computations. Our results yield a charge of -0.119 for each carbon atom and a charge of +0.261 for each hydrogen atom. Within the ring system, all the $\mathrm{C}-\mathrm{C}$ bonds have carbon termini with an $s: p$ ratio of 1.77 (table S5), smaller than the value of 2 for a 'perfect' $s p^{2}$ hybrid carbon atom (as may be expected in benzene).

The calculated NICS(1) value of -9.504 (table 4) for the tropyl cation $\mathbf{1}$ is in line with its well-established aromaticity. Though $\mathbf{1}$ may be considered the most aromatic of all $\mathrm{C}_{7} \mathrm{H}_{7}^{+}$isomers, other less stable isomers $(7,8,10,12,13,18$ and 25) are characterized by larger (more negative) NICS values, which indicates a lack of good correlation between stability and magnitude of the NICS index.

For the $C_{2 v}$ benzyl cation 2 , the geometry and charges point to delocalization of positive charge on the exocyclic C7 atom mostly onto the ortho and para carbons. The geometries here resemble those obtained by 

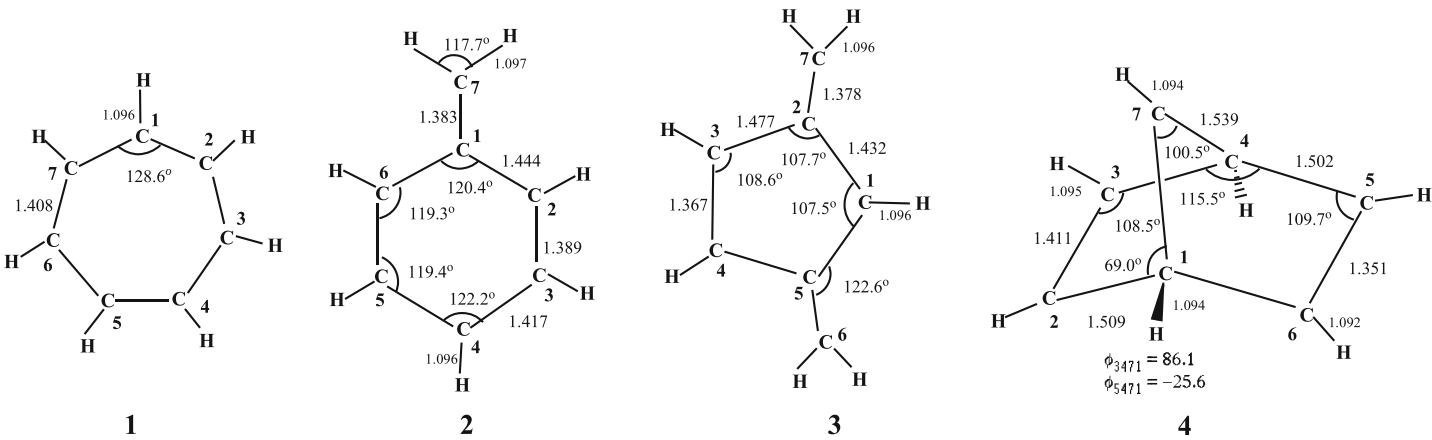

4

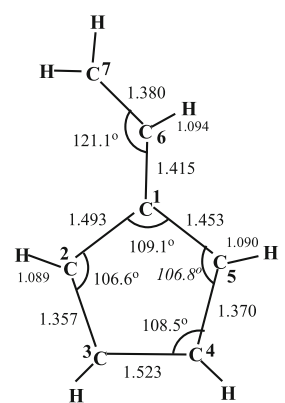

5

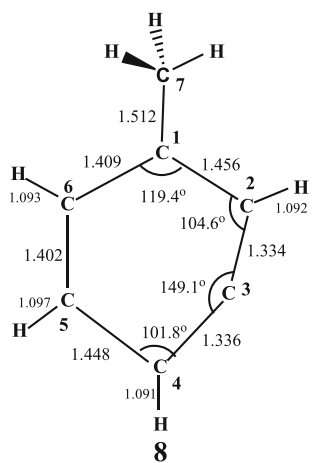

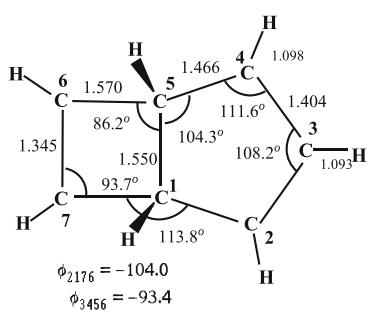

6

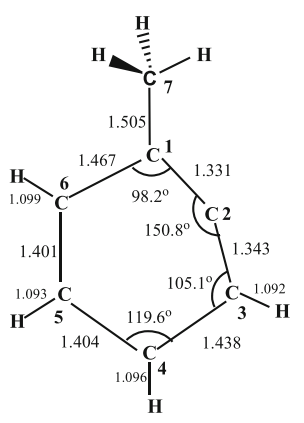

7

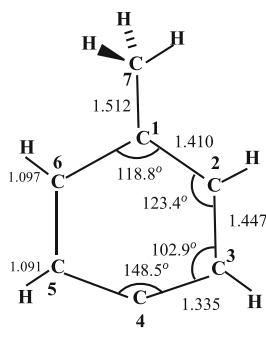

10

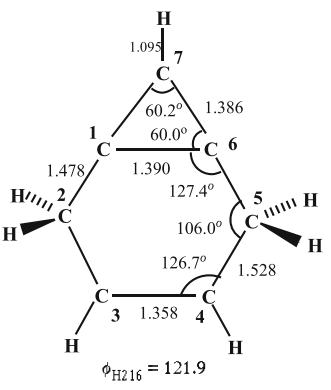

13

Figure 3. Bond lengths and bond angles for isomers 1 to 13 (MP2/cc-pVDZ values).

the DZP CCSD(T), B3LYP/6-31G(d,p) and MINDO/3 methods. ${ }^{20,24,36}$ The $\mathrm{C}-\mathrm{H}$ group net positive charges follow the decreasing order $\mathrm{C} 7>\mathrm{C} 4>(\mathrm{C} 2$ and $\mathrm{C} 6)>$ (C3 and C5). The chief single resonance structure predicted has unit charge on the $\mathrm{C} 7$ atom (a $p$-alkyl cation centre). One other important form has positive charge on the $\mathrm{C} 4$ atom (figure 1). Note that greater positive charge tends to be borne by atoms with $s: p$ ratios less than 2 (table S5). The appreciable NICS(1) value of -6.456 for the benzene moiety indicates aromatic 


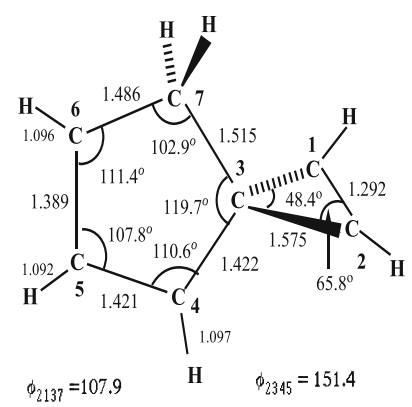

14

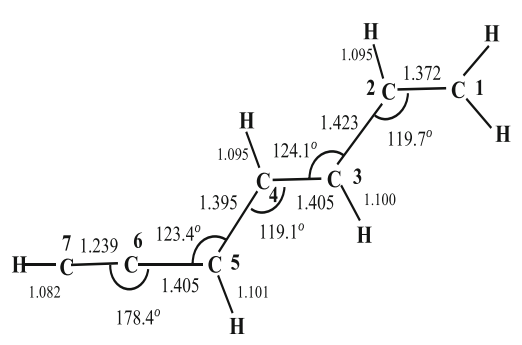

15

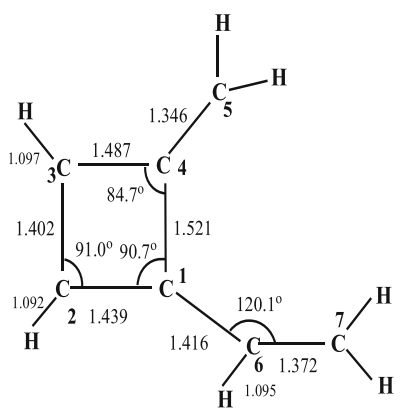

16

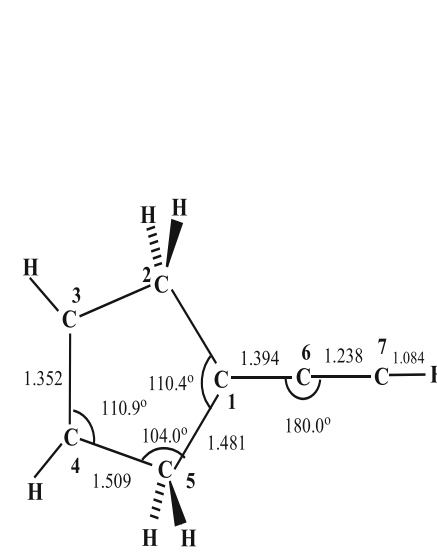

17

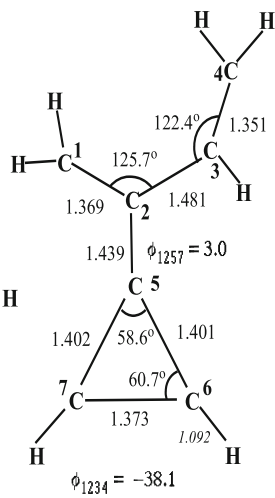

18

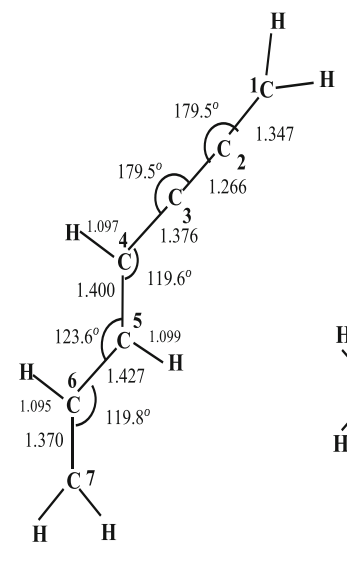

19

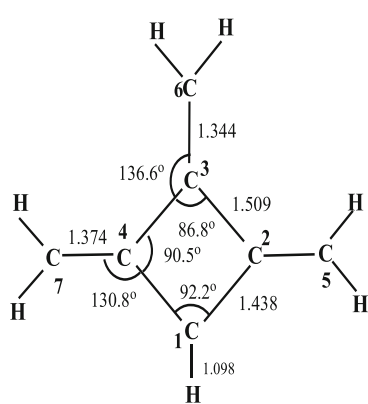

20

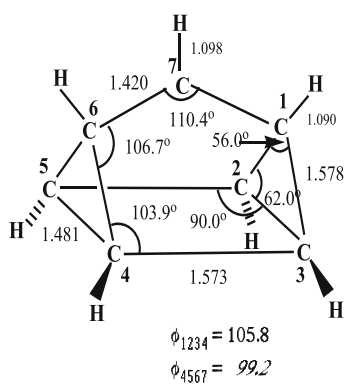

21

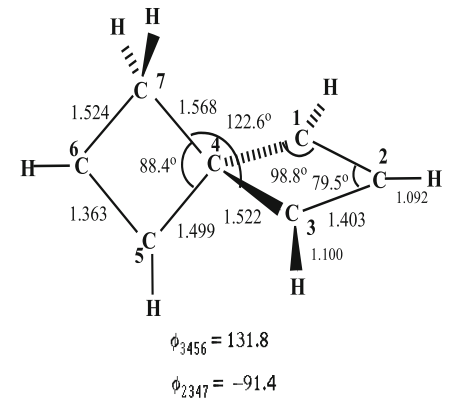

22

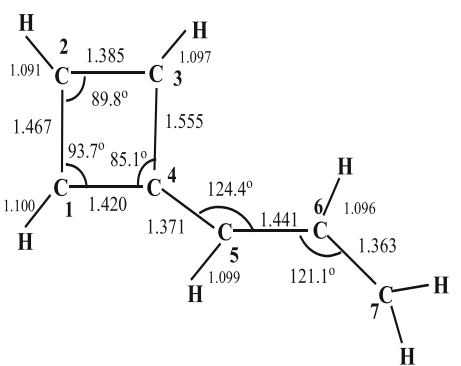

23

Figure 4. Bond lengths and bond angles for isomers 14 to 23 (MP2/cc-pVDZ values).

character for this ring, which is due to the aromatic sextet present as a neutral entity (not to any aromatic delocalization of charge).

The $C_{2 v}$ 2,5-dimethylene-cyclopentenyl cation $\mathbf{3}$ is stabilized by two equivalent allylic resonances (C1-C2$\mathrm{C} 7$ and $\mathrm{C} 1-\mathrm{C} 5-\mathrm{C} 6$ ), an effect more prominent than conjugation over the C7-C2-C3-C4-C5-C6 chain. This is inferred from the short C3-C4 bond length $(1.367 \AA)$ compared to the $\mathrm{C} 2-\mathrm{C} 3$ and $\mathrm{C} 4-\mathrm{C} 5$ bond lengths (1.477 $\AA$ ). The $\mathrm{C} 1$ atom is the most positively charged carbon $(+0.187)$, suggesting the chief resonance structure to be that with unit charge on this sec-alkyl $\mathrm{C} 1$ atom (figure 1). While the NICS(0) value is positive, the negative NICS(1) value of -3.647 seems to point to some degree of aromatic character in the cyclopent-3,4-enyl ring moiety.

The 7-norborna-1,4-dienyl cation $\mathbf{4}$ has only one of the two lateral pi bonds delocalized over the positively charged apical C7 atom. Cation $\mathbf{4}$ does not have $C_{2 v}$ symmetry similar to norbornadiene, but $C_{s}$ symmetry, 


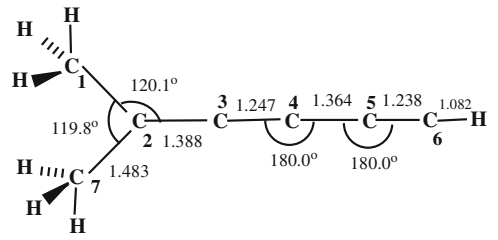

24

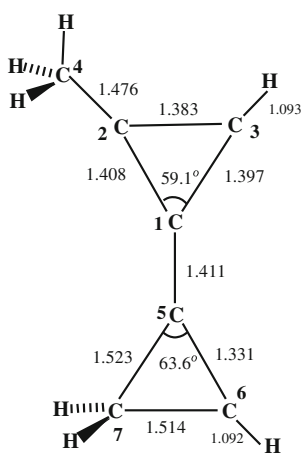

25

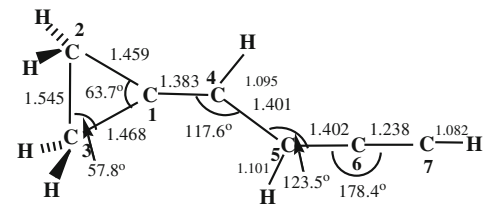

26

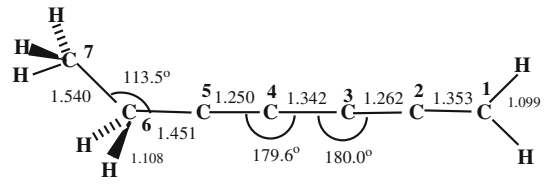

27

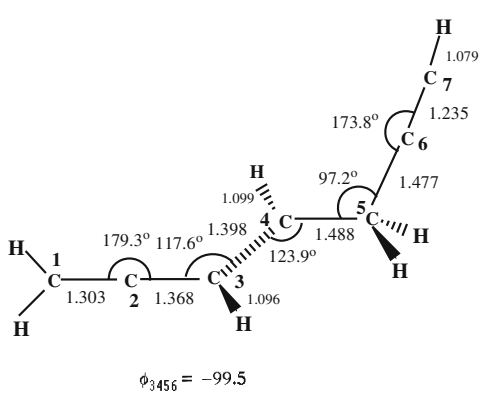

28

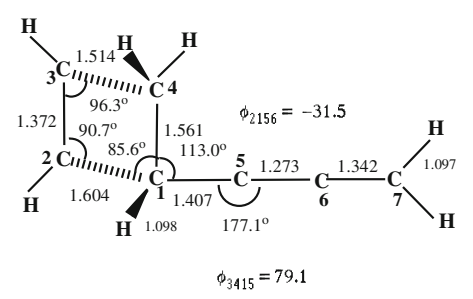

29

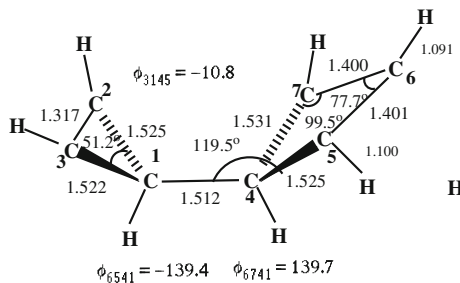

30

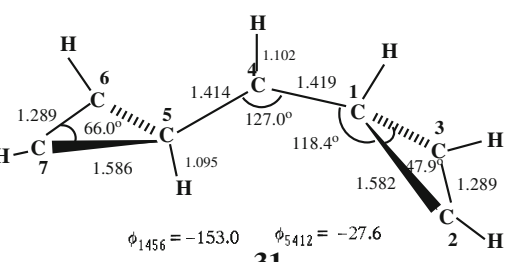

31

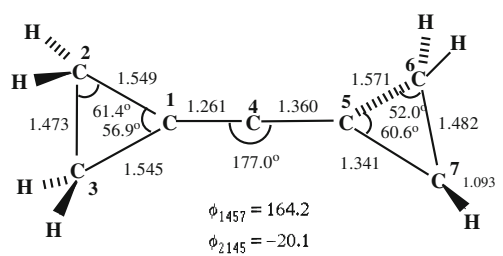

32

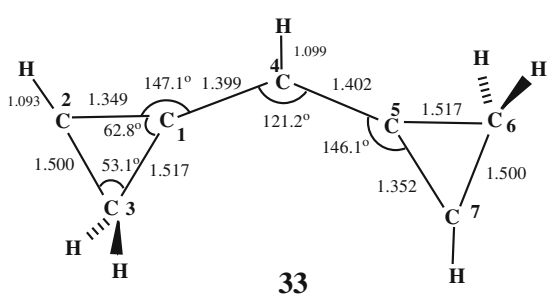

33

Figure 5. Bond lengths and bond angles for isomers 24 to 33 (MP2/cc-pVDZ values).

and the $\mathrm{C} 7$ proton points to one side, not straight up. This is confirmed by NMR data ${ }^{37-41}$ which shows that $\mathrm{C} 2 / \mathrm{C} 3$ protons and $\mathrm{C} 5 / \mathrm{C} 6$ protons are not equivalent. The $C_{2 v}$ structure is a transition state. The $C_{s}$ structure is supported by this study, with the $\mathrm{C} 7$ proton pointing away from the $\mathrm{C} 5-\mathrm{C} 6$ bond. The $\mathrm{C} 2-\mathrm{C} 3$ bond is longer than the C5-C6 bond. Non-classical delocalization of one pi bond thus makes 4 rank fourth in the stability order. The resonance hybrid is shown in figure 1.
The 1-vinylcyclopentadienyl ion $\mathbf{5}$ has an antiaromatic cyclopentadienyl cation moiety in one structure, conflicting with the good degree of stability accorded here. Our B3LYP/ 6-31G(d,p) calculations on the cyclopentadienyl cation predict Jahn-Teller distortion favours the $C_{2 v}$ structure; the more symmetrical $\mathrm{C}_{5 h}$ structure is an anti-aromatic transition state. Allylic resonance over the $\mathrm{C} 1-\mathrm{C} 6-\mathrm{C} 7$ moiety reduces contribution of the cyclo-pentadienyl ion moiety (note unequal $\mathrm{C}-\mathrm{C}$ bond lengths in the five-membered ring). 
Table 4. NICS(0) and NICS(1) values for cyclic moieties present in various $\mathrm{C}_{7} \mathrm{H}_{7}^{+}$cation isomers at the B3LYP/cc-pVDZ level (in ppm).

\begin{tabular}{lccc}
\hline Cation & Moiety & NICS $(0)$ & NICS(1) \\
\hline $\mathbf{1}$ & Tropylium ring & -6.215 & -9.594 \\
$\mathbf{2}$ & Benzene ring & -1.321 & -6.456 \\
$\mathbf{3}$ & Cyclopent-3,4-enyl & +2.145 & -3.647 \\
$\mathbf{5}$ & Cyclopentadienyl & +34.614 & +20.164 \\
$\mathbf{6}$ & Cyclopent-2,3-enyl & +1.492 & -4.902 \\
$\mathbf{7}$ & Phenyl cation ring & -17.168 & -11.965 \\
$\mathbf{8}$ & Phenyl cation ring & -16.095 & -12.197 \\
$\mathbf{1 0}$ & Phenyl cation ring & -16.366 & -11.868 \\
$\mathbf{1 1}$ & Cyclopent-2,3-enyl & -0.242 & -0.111 \\
$\mathbf{1 2}$ & Cycloprop-2,3-enyl & -23.269 & -11.540 \\
$\mathbf{1 3}$ & Cycloprop-2,3-enyl & -20.887 & -14.045 \\
$\mathbf{1 4}$ & Cyclopent-2,3-enyl & +1.050 & -5.132 \\
$\mathbf{1 6}$ & Cyclobut-2,3-enyl & +15.306 & +1.782 \\
$\mathbf{1 7}$ & Cyclopent-3,4-enyl & +4.084 & -3.464 \\
$\mathbf{1 8}$ & Cycloprop-2,3-enyl & -22.496 & -13.719 \\
$\mathbf{2 0}$ & Cyclobutyl & +9.198 & -2.407 \\
$\mathbf{2 3}$ & Cyclobut-2,3-enyl & +31.922 & +14.860 \\
$\mathbf{2 5}$ & Cycloprop-2,3-enyl & -22.298 & -12.476 \\
\hline
\end{tabular}

Three allylic resonances (C1-C6-C7, C1-C5-C4 and C1-C2-C3) stabilize cation $\mathbf{5}$.

The chief canonical form for $\mathbf{5}$ has an undelocalized cyclopentadienyl cation moiety (figure 1), with the C2$\mathrm{C} 3$ and C4-C5 double bonds. Here, the anti-aromatic character expected is well borne out by the large positive NICS(0) and NICS(1) values of +34.615 and +20.164 , respectively, obtained for this ring moiety.

The bicyclo[3.2.0]heptadienyl cation $\mathbf{6}$ is stabilized by extensive allylic charge delocalization in the fivemembered ring (C2-C3 and $\mathrm{C} 3-\mathrm{C} 4$ bond lengths of $1.404 \AA$ ). The $\mathrm{C} 2$ and $\mathrm{C} 4$ atoms are the only positively charged carbons, and their $s: p$ ratios of 1.87 to 2.00 point to their basically $s p^{2}$ hybrid character. Other carbons $\left(s p^{2}\right.$ or $\left.s p^{3}\right)$ bear negative charge, while the C6-C7 double bond is not delocalized (figure 1).

In the ortho tolyl cation 7, positive charge on the $\mathrm{C} 2$ atom $(+0.591)$ is localized, as in the phenyl cation. The $\mathrm{C} 2$ atom has $s p$ character (see $\mathrm{C} 1-\mathrm{C} 2-\mathrm{C} 3$ angle of $150.8^{\circ}$ and the short $\mathrm{C} 1-\mathrm{C} 2$ and $\mathrm{C} 2-\mathrm{C} 3$ bond lengths). A similar situation is seen in the meta tolyl cation $\mathbf{8}$ with $s p$ character in the $\mathrm{C} 3$ atom (charge +0.625$)$. The para tolyl cation $\mathbf{1 0}$ is analogous to the ortho and meta tolyl cations, with $s p$ character of the positively charged $\mathrm{C} 4$ atom and unequal ring $\mathrm{C}-\mathrm{C}$ bonds. Geometries of $\mathbf{7 , 8}$ and $\mathbf{1 0}$ mirror earlier results ${ }^{19,20,23,24,36}$ pointing to strained rings with charge localized on the $s p$ carbon. The distorted geometry diminishes the stabilizing effect of the aromatic sextet (although still formally present since the ring is planar). The $s: p$ ratios for the positively charged carbon atom in $\mathbf{7 , 8}$ and $\mathbf{1 0}$ are all close to 1.00 , indicating basically $s p$ character for this atom. This is so in spite of the non-collinear arrangement of the other atoms around this charged atom.

The 1'-vinyliumcyclopenta-1,4-diene ion 9 has an exocyclic $s p \mathrm{C}^{\prime}$ atom (see the near $180^{\circ}$ bond angle). The allenic $\mathrm{C} 1-\mathrm{Cl}^{\prime}-\mathrm{C} 2^{\prime}$ moiety has its $-\mathrm{CH}_{2}$ group perpendicular to the ring and a $\mathrm{C}^{\prime}-\mathrm{C}^{\prime}$ double bond. The C4-C5 double bond is localized, but positive charge is delocalized over the $\mathrm{C} 2$ and $\mathrm{C}^{\prime}$ atoms - the chief stabilizing feature for 9 . The $s p \mathrm{C}^{\prime}$ atom bears large positive charge of +0.363 a.u. - a destabilizing feature.

The tricyclo[3.2.0.0 $0^{1,6}$ ]heptenyl ion $\mathbf{1 1}$ has its $\mathrm{C} 5$ C6 double bond (1.384 $\AA$ ) in allylic resonance with the $\mathrm{C} 7$ atom (charge +0.106$)$. The rather long $\mathrm{C} 1-\mathrm{C} 3$ bond length (1.596 $\AA$ ) suggests non-classical sigma bond inter-conversion with the $\mathrm{C} 3-\mathrm{C} 7$ pi bond. Both allylic resonance and sigma-pi bond delocalization serve to stabilize 11, while the two strained cyclopropane rings are destabilizing features.

The 2,3-divinylcyclopropenyl ion $\mathbf{1 2}$ should be stabilized by the aromatic cyclopropenyl cation ring, and by allylic resonance between the exocyclic vinyl groups and the positive charge on the $\mathrm{C} 3 / \mathrm{C} 2$ atoms. However, a high degree of delocalization is not corroborated by the geometry. The vinyl $\mathrm{C}-\mathrm{C}$ bonds are short $(1.358 \AA)$ compared to the $\mathrm{C} 3-\mathrm{C} 4$ and $\mathrm{C} 2-\mathrm{C} 6$ bonds $(1.438 \AA)$. The three cyclopropenylium C-C bond lengths are unequal. A suitable form for $\mathbf{1 2}$ has 
positively charged $\mathrm{C} 2 / \mathrm{C} 3$ atoms along with $\mathrm{C} 1-\mathrm{C} 2$ and C3-C1 double bonds. The NICS(1) index value of -11.540 at the cyclopropenyl ring points to the aromaticity of this moiety. The three carbons of this ring moiety have $s: p$ ratios of 2.40 to 2.54 , where the value appreciably above 2.00 arises out of the strained ring.

The bicyclo[4.1.0]heptadienyl ion $\mathbf{1 3}$ is stabilized by the aromatic cyclopropenyl cation moiety with its concentrated positive charge and large NICS(1) value of -14.045 . Its three nearly equal $\mathrm{C}-\mathrm{C}$ bonds indicate full aromatic delocalization, though the $\mathrm{C} 3-\mathrm{C} 4$ bond remains double. The $\mathrm{C} 7$ atom of this ring bears an $s: p$ ratio of 2.37 whose value (higher than the normal value for an $s p^{2}$ carbon) may be linked to the destabilizing ring strain present. The unstrained six-membered ring is a stabilizing feature. Figure 1 depicts an appropriate resonance hybrid with fully delocalized charge in the three-membered ring.

The non-planar spiro[2.4]hept-1,6-dienyl ion $\mathbf{1 4}$ is stabilized by allylic resonance in the cyclopentenyl ring, with positively charged $\mathrm{C} 4$ and $\mathrm{C} 6$ atoms. The strained cyclopropene ring is a destabilizing feature. Figure 1 depicts an appropriate hybrid structure.

The hept-1,3-diene-6-ynyl ion $\mathbf{1 5}$ is the most stable acyclic isomer in this series and shows the stabilizing effects of cyclic structure in general. The C7-C6 partial triple $s p-s p$ bond $(1.239 \AA)$ and partial double C3-C4, C4-C5 and C5-C6 bonds (1.405, 1.395 and $1.405 \AA$ A respectively) show charge and pi bond delocalization over the C7-C6-C5-C4-C3 chain. A good resonance structure for $\mathbf{1 5}$ has charge and pi bond delocalization over this framework (figure 1), where the maximal carbon charge of +0.143 a.u. is located on the $s p^{2}$ $\mathrm{C} 3$ atom, and not on the $s p$ hybrid $\mathrm{C} 7$ atom.

The 4-methylene-1-vinylcyclobutenyl ion $\mathbf{1 6}$ shows $\mathrm{C}-\mathrm{C}$ bond alternation, with a double bond between the exocyclic $-\mathrm{CH}_{2}$ group and the cyclobutene ring, along with unequal $\mathrm{C}-\mathrm{C}$ bond lengths in the cyclobutenyl ring. The $\mathrm{C} 1-\mathrm{C} 6$ and $\mathrm{C} 6-\mathrm{C} 7$ bond lengths and the $\mathrm{C} 1$ atom charge $(+0.305)$ do indicate some allylic resonance (the only stabilizing feature for 16). The positive NICS(0) and NICS(1) values point to lack of aromaticity.

The 1-ethynenylcyclopent-3-enyl cation 17 does not involve much resonance between the $\mathrm{C} 6-\mathrm{C} 7$ triple bond and the $\mathrm{C} 1$ atom charge, where the $s p^{2} \mathrm{C} 1$ atom bears the maximal carbon positive charge $(+0.474$ a.u. $)$ and not the $s p \mathrm{C} 7$ atom. The cyclopentene ring has no resonance delocalization. Figure 1 depicts a suitable structure for 17.

In the $1^{1}$ (but-1,3-dienyl)cyclopropenyl ion 18, stabilization from the cyclopropenylium moiety and resonance between the exocyclic butadienyl group and charged ring $\mathrm{C} 5$ atom is not extensive. The three cyclopropenyl $\mathrm{C}-\mathrm{C}$ bond lengths are unequal. The $\mathrm{C} 1-\mathrm{C} 2$ and $\mathrm{C} 3-\mathrm{C} 4$ bond lengths do not indicate much resonance. Small ring strain is a destabilizing feature. A suitable structure for $\mathbf{1 8}$ (figure 2) has a positively charged $\mathrm{C} 5$ atom, and localized $\mathrm{C} 1-\mathrm{C} 2, \mathrm{C} 3-\mathrm{C} 4$ and C6-C7 double bonds.

The 1,2,4,6-heptatetraenyl ion 19 has a triple C2$\mathrm{C} 3 s p-s p$ bond, a single C1-C2 bond, and the C4-C5 and C6-C7 double bonds. Lack of resonance stabilization, along with the charged $s p \mathrm{C} 3$ atom $(+0.237$ a.u. $)$ suggests the structure shown in figure 2.

The $C_{2 v}$ planar trimethylenecyclobutyl cation $\mathbf{2 0}$ has a cyclobutyl ring with three $-\mathrm{CH}_{2}$ groups. Diminished resonance and small ring strain make $\mathbf{2 0}$ quite unstable. Ring strain is apparent in the $s: p$ ratio of 2.48 for the $\mathrm{C} 2$ and $\mathrm{C} 4$ atoms. Maximal positive charge resides on the $s p^{2} \mathrm{C} 1$ atom ( $s: p$ ratio is 2.05). Figure 2 gives a suitable structure for $\mathbf{2 0 .}$

The saturated non-planar tetracyclo[3.2.0.0 $\left.0^{2,7} \cdot 0^{4,6}\right]$ heptyl cation $\mathbf{2 1}$ has no scope for any delocalization, the sec-alkyl cation C7 centre being the only positively charged carbon. Saturation, ring strain and lack of resonance figure in the structure given in figure 2.

The spiro[3.3]heptadienyl cation $\mathbf{2 2}$ has two fourmembered rings spiro to each other. The charged cyclobutyl ring shows allylic resonance over the C1C2-C3 moiety. The other ring (cyclobutenyl) is highly strained. A suitable structure is shown in figure 2.

The planar 4-propylidenylcyclobutenyl cation $\mathbf{2 3}$ has a cyclobutenyl ring attached to a propylidenyl group via a double bond. Bond alternation points to lack of delocalization. The long C3-C4 bond length (1.555 $\AA$ ) arises out of strain. These destabilizing features appear in the structure shown in figure 2.

The 2-methylhexa-3,5-diyne-2-yl cation $\mathbf{2 4}$ has a linear $\mathrm{C} 2-\mathrm{C} 3-\mathrm{C} 4-\mathrm{C} 5-\mathrm{C} 6-\mathrm{H}$ chain with triple $\mathrm{C} 3-\mathrm{C} 4$ and $\mathrm{C} 5-\mathrm{C} 6$ bonds that show little delocalization with the positively charged $s p^{2} \mathrm{C} 2$ atom (charge +0.403 ). Despite pi bond delocalization over the C2-C3-C4-C5C6 chain, the positively charged $s p \mathrm{C} 4$ and $\mathrm{C} 6$ atoms destabilize cation 24.

The cycloprop-1'-enyl-2-methylcyclopropenyl cation 25 has two three-membered rings linked by an $s p^{2}$ carbon. Both the cyclopropenyl rings have unequal $\mathrm{C}-\mathrm{C}$ bond lengths which reduce aromatic stabilization, leading to the unstable structure shown in figure 2.

The planar 4-cyclopropylidinylbut-1-ynyl cation $\mathbf{2 6}$ has a cyclopropyl ring bonded to a butenynyl group which is much more strained than the saturated cyclopropyl ring. Charge localization is evident on the $\mathrm{C} 1$ atom, while the $\mathrm{C} 1-\mathrm{C} 4$ and $\mathrm{C} 6-\mathrm{C} 7$ bonds show dipolar character. Ring strain and absence of pi bond and charge resonance destabilize $\mathbf{2 6}$. 
The hepta-1,2-diene-4-ynyl cation 27 has a linear sixcarbon chain with triple $\mathrm{C} 2-\mathrm{C} 3$ and $\mathrm{C} 4-\mathrm{C} 5$ bonds and charge localized on the terminal C5 atom. Noticeable positive charge on the $s p$ hybrid $\mathrm{C} 3$ and $\mathrm{C} 5$ atoms is a destabilizing feature. This together with the lack of delocalization assign to $\mathbf{2 7}$ the unstable resonance form shown in figure 2.

The non-planar hepta-1,2-diene-6-ynyl cation $\mathbf{2 8}$ has a seven-carbon chain. Scope arises for many canonical forms with positively charged $s p$ carbons. The C1-C2 bond is highly dipolar. Positively charged $s p$ carbons, dipolar C-C bonds and lack of resonance show up in the unstable structure for $\mathbf{2 8}$ (figure 2).

The 1-(cyclo-2 ${ }^{1}$-enyl)prop-1,2-dienyl cation 29 contains a highly strained cyclobutene ring bonded to an allenyl group. The $s p$ C5 atom bears appreciable positive charge which, together with ring strain and lack of resonance make 29 very unstable (figure 2).

The $1,1^{1}$-cyclopropenylcyclobutenyl ion $\mathbf{3 0}$ has the highly strained cyclopropene and cyclobutenylium rings. Allylic delocalization in the C5-C6-C7 moiety yields equal C5-C6 and C6-C7 bond lengths, but the small C5-C6-C7 angle (77.7 $)$ sharply diminishes this effect. Unsaturated small ring strain is the main destabilizing factor for $\mathbf{3 0}$.

The non-planar $C_{2 v}$ dicycloprop-2-enylmethylenyl cation 31 has two cyclopropene rings bonded via the positively charged $\mathrm{C} 4$ atom. No resonance delocalization of charge is seen in $\mathbf{3 1}$, which, along with its two highly strained rings leads to high instability.

The non-planar cyclopropylcyclopropylidinylmethynenyl ion $\mathbf{3 2}$ has a cyclopropane ring and a cyclopropenyl ring linked by an $s p \mathrm{C} 4$ atom bearing large positive charge $(+0.357)$. The $\mathrm{C} 1-\mathrm{C} 4-\mathrm{C} 5$ allene moiety makes the two rings perpendicular to each other. Small ring strain and localized positive charge on the $s p \mathrm{C} 4$ atom account for the high instability.

The most unstable dicycloprop-1-enylmethynyl isomer $\mathbf{3 3}$ resembles $\mathbf{3 1}$ except that $\mathbf{3 3}$ has scope for two allylic delocalizations, one on either side of the central $s p^{2} \mathrm{C} 4$ atom. However, this imparts double bond character to the C1-C4 and C4-C5 bonds, a source of additional strain. Enhanced small ring strain leads to the high instability of $\mathbf{3 3}$.

Note that ring strain, whether involving charged centres or neutral carbons, has an effect upon the $s: p$ ratios for the atoms involved. Trivalent carbons bearing partial positive charge in a strained ring are associated with $s: p$ ratios larger than 2.00 , while charge delocalization reduces the $s: p$ ratio below 2.00. Divalent carbons with partial positive charge, however, all retain $s: p$ ratios of value close to 1.00 .

\section{Conclusions}

This computational study on the structure, stability and charge distribution of 33 isomers on the $\mathrm{C}_{7} \mathrm{H}_{7}^{+}$energy surface yields the following conclusions.

(i) All $33 \mathrm{C}_{7} \mathrm{H}_{7}^{+}$isomeric structures were predicted as true minima by all four methods of study. Their optimized geometries corresponded well to their valence bond formulae, as well as with the optimized geometries obtained previously for a few of the systems.

(ii) Stability orders for these $33 \mathrm{C}_{7} \mathrm{H}_{7}^{+}$isomers, derived from the four methods used here, were compared. The B3LYP and MP2 stability orders correlated well with each other, though the HF stability order differed to some extent. Relative stabilities estimated on the basis of total energy and on the basis of free energy correlated well with each other.

(iii) Relative stability of isomers was consistently linked to pertinent structural features applied qualitatively, such as aromaticity, allylic and pi bond resonance, small ring strain, unsaturation, non-classical structure and carbon atom hybridization state.

(iv) Natural population analysis based on the MP2 method located the site(s) of maximal positive charge. Charge distribution and optimized geometry considered together led to assignment of appropriate resonance structures/hybrids for all $33 \mathrm{C}_{7} \mathrm{H}_{7}^{+}$isomers (figures 1 and 2), something which general considerations alone cannot meaningfully accomplish.

(v) The NICS index for aromaticity predicts greater aromaticity for cyclopropenylium moieties over the benzene moiety and the tropylium species, which may not be consistent with other measures of aromaticity. However, this index does differentiate well between non-aromatic, anti-aromatic and aromatic rings.

(vi) The $s: p$ ratios for various carbon atoms, as deduced from NHO analysis, indicate that situation of positive charge upon an $s p$ hybrid carbon is a destabilizing feature.

\section{Supplementary Information}

Tables S1 to S9, figures S1 to S13, as well as the Cartesian coordinates for optimized geometries of all species (in the file SuppInfoGeom) may be obtained at the website of this journal (www.ias.ac.in/chemsci).

\section{Acknowledgements}

The authors thank the Council for Scientific and Industrial Research (CSIR), Government of India, for computational facilities procured through Sanction Letter No 34(1481)/11/EMR-II. 


\section{References}

1. Pachuau Z, Kharnaior K S and Lyngdoh R H D 2013 J. Chem. Sci. 125365

2. Kharnaior K S 2013. Ph.D. Dissertation North Eastern Hill University Shillong India

3. Lifshitz C 1994 Acc. Chem. Res. 27138

4. Sagi N, Yamamoto Y, Nagaoka K, Takamuku S and Sakurai H 1974 Bull. Chem. Soc. Japan 471387

5. Lifshitz C, Gotkis Y, Ioffe A, Laskin J and Shaik S 1993 Int. J. Mass Spectrom. Ion Processes 125 R7

6. Bombach R, Dannacher J and Stadelmann J P 1983 Chem. Phys. Lett. 95259

7. Dunbar R C 1973 J. Am. Chem. Soc. 95472

8. Shen J, Dunbar R C and Olah G A 1974 J. Am. Chem. Soc. 966227

9. Moon J H, Choe J C and Kim M S 2000 J. Phys. Chem. A104 458

10. Schulze S, Paul A and Weitzel K M 2006 Int. J. Mass Spectrom. 252189

11. Ausloos P 1982 J. Am. Chem. Soc. 1045259

12. Malow M, Penno M and Weitzel K M 2003 J. Phys. Chem. A107 10625

13. Hwang W G, Moon J H, Choe J C and Kim M S 1998 J. Phys. Chem. A102 7512

14. Oh S T, Choe J C and Kim M S 1996 J. Phys. Chem. 10013367

15. Baer T, Morrow J C, Shao J D and Olesik S 1988 J. Am. Chem. Soc. 1105633

16. (a) Morgenthaler L N and Eyler J R 1981 Int. J. Mass Spectrom. Ion Processes 37 153; (b) Olesik S, Baer T, Morrow J C, Ridal J J, Buschek J and Holmes J L 1989 Org. Mass Spectrom. 241008

17. Kim Y H, Choe J C and Kim M S 2001 J. Phys. Chem. A105 5751

18. Traeger J C and Kompe B M 1990 Int J. Mass Spectrom. Ion Process. 101111
19. Dewar M J S and Landman D 1977 J. Am. Chem. Soc. 992446

20. Cone C, Dewar M J S and Landman D 1977 J. Am. Chem. Soc. 99372

21. Smith B J and Hall N E 1997 Chem. Phys. Lett. 279165

22. Nicolaides A and Radom L 1994 J. Am. Chem. Soc. 116 9769

23. Shin S K 1997 Chem. Phys. Lett. 280260

24. Shin C H, Park K C, Kim S J and Kim B 2002 Bull. Korean Chem. Soc. 23337

25. Lin C Y and Dunbar R C 1994 J. Phys. Chem. 981369

26. Buhl M and Wullen C V 1995 Chem. Phys. Lett. 24763

27. Schleyer P V R, Maerker C, Dransfeld A, Jiao H and Hommes N J R V E 1996 J. Am. Chem. Soc. 1186317

28. Pauling L J 1931 J. Am. Chem. Soc. 531367

29. Foster J P and Weinhold F 1980 J. Am. Chem. Soc. 102 7211

30. Becke A D 1988 Phys. Rev. A38 3098

31. Becke A D 1993 J. Chem. Phys. 985648

32. Lee C, Yang W and Parr R G 1988 Phys. Rev. B37 785

33. Frisch M J et al. GAUSSIAN 09, Revision A.1, Gaussian Inc., 2009, Wallingford, USA

34. Scott A P and Radom L 1996 J. Phys. Chem. 10016502

35. (a) Reed A E, Curtiss L A and Weinhold F 1988 Chem. Rev. 88 899; (b) Reed A E, Weinstock R B and Weinhold F 1985 J. Chem. Phys. 83735

36. Ignatyev I S and Sundius T 2000 Chem. Phys. Lett. 326 101

37. McLafferty F W and Winkler J 1974 J. Am. Chem. Soc. 965182

38. Park J and Shin J H 1999 Bull. Korean Chem. Soc. 20 667

39. Lustgarten R K, Brookhart M and Winstein S 1972 J. Am. Chem. Soc. 942347

40. le Noble W J, Merbach A E and Schulman E M 1981 J. Org. Chem. 463352

41. Story P R, Snyder L C, Douglas D C, Anderson E W and Kornegay R L 1963 J. Am. Chem. Soc. 853630 